\title{
Estratégias para a conservaçào da fauna amazônica
}

\author{
José Márcio Ayres * \\ Robin Best *
}

A Amazônia com seus 7 milhões de $\mathrm{km}^{2}$ apresenta uma diversidade florística e faunística incomparável a qualquer outro biótopo do planeta (Fittkau, 1969). Existem, somente na parte brasileira, mais espécies de primatas que em qualquer outro país, aproximadamente 2.000 espécies de peixes (Roberts, 1972; Junk, 1975) e cerca de $11 \%$ das espécies de aves conhecidas no mundo inteiro (Amadon, 1973; Sick, 1972; Meyer de Schauensee, 1966). Com o aumento recente das pesquisas taxonômicas, na região, estes números têm sido incrementados a cada ano que passa; no entanto, como veremos adiante, o conhecimento sobre a biologia das espécies encontra-se ainda num estágio muito rudimentar.

Apesar de a Amazônia possuir uma densidade demográfica humana muito baixa em relação ao restante do continente americano, as taxas de desmatamento têm-se mostrado bastante elevadas. Deste modo, estamos na iminência de perder, sem ao menos tomar consciência, parte de uma fauna que poderia trazer para o homem amazônico benefícios, tais como :

a) patrimônio biológico e cultural;

b) recurso natural de extrativismo e turístico;

c) fonte de proteínas e nutrientes.

Para chegar ao estado evolutivo atual a Amazônia levou alguns milhares de anos. Somente nas últimas duas décadas a região foi, como ainda continua sendo, sumamente modificada, tanto cultural quanto estruturalmente e os reflexos desta alteração começam a ser percebidos agora (Schubart, 1977; Ianni, 1979).

Neste curto período, pelo menos $10 \%$ de toda a cobertura florestal da região foi alterada (Tardin et al., 1979; Goodland \& Irwin, 1975) e das conseqüências dessa alteração pouco se sabe ainda. Acredita-se no entanto, que, no mínimo, 20 espécies de mamíferos, 5 espécies de aves e 3 espécies de répteis já têm problema com relação a seus estoques naturais $e$ que ainda, 5 destas podem ser consideradas em perigo de extinção, dada às altas taxas de desmatamentos, à caça comercial e de subsistência. Discutiremos, a seguir, as 3 principais causas que colocam em risco a fauna da biota amazônica brasileira, e tentaremos traçar, com base nos conhecimentos atuais disponíveis sobre a biologia das espécies, as diretrizes básicas para a conservação da fauna local.

\section{DESMATAMENTOS EM GERAL}

$\mathrm{Na}$ década de 60 , houve uma grande modificação sócio-econômica na região amazônica. Basicamente, dois acontecimentos assinalaram estas mudanças : a construção das grandes rodovias como a Belém-Brasília e Transamazônica, e a decisão da SUDAM de modificar sua política de incentivos fiscais, no sentido de gerar e dinamizar as atividades agropecuárias (Santos, 1977). A partir destes eventos, a destruição dos habitats cresceu, colocando decisivamente em risco toda a fragilidade do ecos. sistema amazônico.

\section{COLONIZAÇÃo}

Com a implantação do sistema rodoviário, a exploração dos ambientes de terra firme tornou-se possível em larga escala. Assim, passaram a ser vulneráveis locais cujo acesso estava limitado, já que estes, anteriormente, restringiam-se aos rios navegáveis, paranás, furos, lagos e às proximidades dos maiores centros urbanos como Belém e Manaus (Figura 1).

Como conseqüência da colonização dirigida na Amazônia, foram implantadas estradas, que possibilitando o estabelecimento de famílias em áreas não exploradas, visavam entre outras coisas, a diminuir as tensões sociais do 


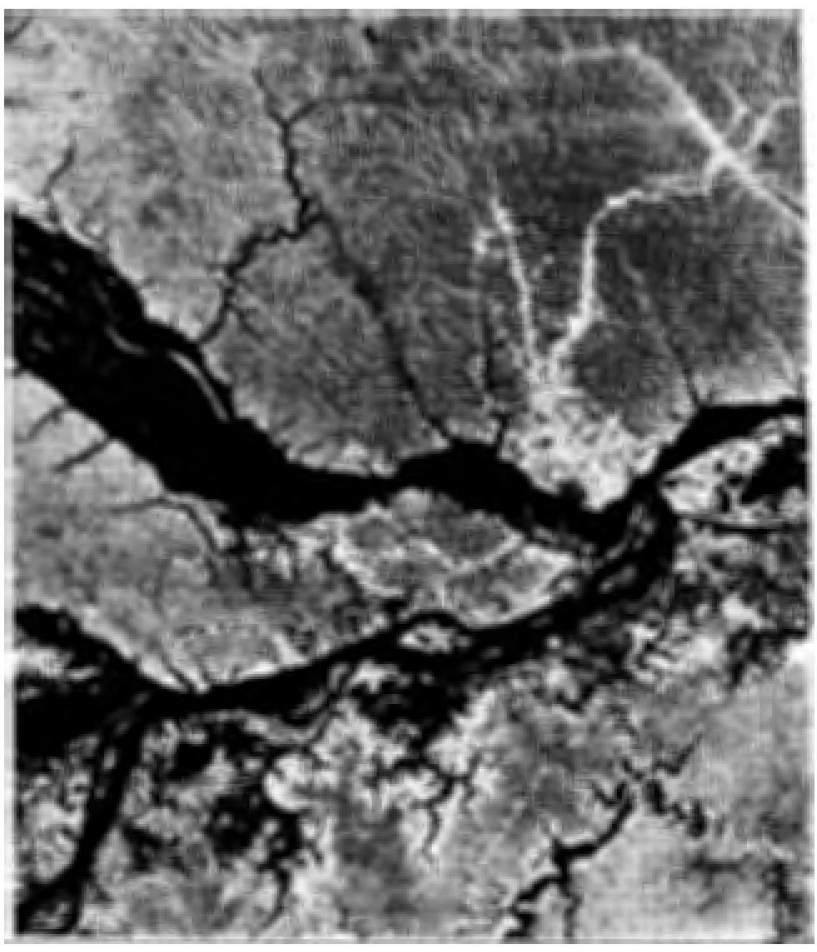

Fig. 1 - Imagens de satélites LANDSAT, da região de Manaus. As partes mais claras da foto mostram as áreas completamente desmatadas (Foto tomada em 31 de julho de 1977/INPE)

nordeste brasileiro. O plano inicial do INCRA era o de estabelecer, na região, 309.000 famílias; no entanto até 1973 somente 5.759 foran assentadas (Cardoso \& Müller, 1978) tendo esse número correspondido a pelo menos 600.000 hectares em desmatamentos. As populações das agrovilas, oriundas de outras regiões do país, enfrentaram, de início, sérios problemas devido ao desconhecimento da re. gião amazônica como também dos problemas relacionados com a sustentabilidade dos seus solos (Smith, 1977; Fearnside, 1979).

Ainda, em conseqüência dos desmatamentos decorrentes da agricultura rudimentar, verificou-se uma redução na fauna vizinha às áreas de colonização, agravando o problema alimentar dessas populações. Deste modo, observou-se o aparecimento de um contingente de mão-de-obra nas áreas de terra firme que poderia ser utilizado para dinamizar o processo de exploração madeireira, agropecuária e mineral (lanni, 1979).

\section{AGROPECUÁRIA}

As maiores responsáveis pelas altas taxas de destruição ambiental na Amazônia brasilei. ra, são as empresas agropecuárias, estimuladas graças à ajuda propiciada pela SUDAM e BASA através dos incentivos fiscais. Até maio de 1974, haviam sido programados pela SUDAM, incentivos para 312 projetos cobrindo uma área maior que 7 milhões de hectares (Cardoso \& Müller, 1978). Em levantamentos recentes, em uma área de 55.000.000 de hec tares no sul do Pará, constatou-se através de imagens transmitidas por satélite LANUSAi que 4.000.000 desta área foram completamente desmatados para a realização de projetos agropecuários de grande porte (Tardin et al., $19 \%$ y . Este é um problema especialmente grave, já que muitas empresas desrespeitam o código tlorestal (lei N. 4.711 de 15 de setembro de 1965) desmatando muito acima das tdxas permitidas pelo órgão responsável peıo controle (Pinto, 1977).

\section{EXPLORAÇÃO MADEIREIRA}

Em toda a Amazônia brasileira, existem aproximadameṇte 480 serrarias, sete fábricas de madeira compensada e uma de tábuas (Schmithüsen, 1978). Apesar de as taxas de exploração madeireira serem ainda baixas em reıação a outras regiões do globo, como a Malasia e Indonésia, a situação pode agravar-se, je que a SUDAM e o IBDF estimulam o extratIvismo madeireiro. Nesse sentido, já exıstem algumas propostas recentes feitas pelos doıs órgãos (Pandolfo, 1978; Schmithüsen, 197) para a exploração através dos "contratos at risco", de 40 milhões de hectares.

Muito embora a retirada seletiva de madei. ra possa empobrecer o ecossistema, isso não agrava de forma crítica a fauna nele presente. Já a exploração intensiva proposta por projetos como os "contratos de risco", promoverá a destruição irreversível desse frágil ecossistema, uma vez que os reflorestamentos, usualmente feitos com monoculturas, limitam a diversidade da fauna e aumentam a susceptibilidade ao fracasso da produção. 
Através de concessões dos órgãos governamentais, algumas empresas madeireiras já ocupam extensos latifúndios, o que pode con; tribuir para a extinção de algumas variedades geográficas inteiramente desconhecidas devido às poucas informações a respeito da biologia das espécies amazônicas. Cabe neste caso, o discutido projeto JARI com mais de .... 1.400.000 de hectares de área (Fearnside \& Rankin, no prelo].

Felizmente, a poluição através da fabricação de celulose e papel não chega ainda a constituir um perigo, dado o baixo número de indústrias na região, porém, não devemos es. quecer-nos que sua ameaça se encontra presente.

\section{MINERAÇÃo}

Atualmente, a mineração apresenta uma distribuição ainda restrita na Amazônia brasileira. No entanto, alguns minérios como a cassiterita, abundante em Rondônia, são encontradas em extensas áreas, podendo, por esse motivo, constituir com sua exploração, um grave risco às populações faunísticas locais.

Entretanto, os perigos mais sérios parecem ser potenciais e são verificados por projetos de exploração de minérios, já aprovados, como é o caso dos minérios de ferro da Serra dos Carajás.

Sabe-se que existem depósitos ferríferos da ordem de 18 bilhões de toneladas, com uma área a ser destruída estimada em 590.800 hectares (Polamazônia, 1977). Esses depósitos encontram-se numa das regiões mais problemáticas para a fauna amazônica, o sul do Estado do Pará (Ayres, 1977).

\section{CAÇA COMERCIAL}

Desde 1967, com o surgimento da lei 5.197 da proteção da fauna, que proíbe a captura de animais silvestres para a comercialização de peles, os dados relativos a esta atividade, desapareceram das estatísticas, ainda que se saiba que ela continua a existir de forma clandestina.

Infelizmente a história do extrativismo na Amazônia servirá como exemplo de exploração sem manejo. Esta atividade pode ser feita com fins de exploração de peles, carne e animais vivos, por exemplo, primatas e peixes ornamentais (Carvalho, 1967).

Das atividades citadas, a mais importante corresponde à exportação de peles, que já vitimou duranie anos, milhares de animais silvestres em toda a Amazônia (Carvalho, 1967; Hidroservice, 1973) (Tabela 1).

TABELA 1 - Produçāo de peles e couros de alguns animais silvestres no Estado do Amazonas entre 1950 e 1965 (Carvalho, 1967).

ESPÉCIES

QUANTIDADES

Jacarés (Melanosuchus niger e

Caiman crocodilus)

7.517 .226

Lontra (Lutra enudris)

3.170

Capivara (Hydrochaeris hydrochaeris)

498.868

Camaleão (Iguana iguana)

1.660

Caititú (Tayassu tajacu) ............. 220.447

Ariranha (Pteronura brasiliensis) ....... 7.510

Onça-pintada (Panthera onca) .......... 11.016

Cobra (várias espécies) ............. 1.703

Gatos (Felis spp.) . . . . . . . . . . . . 7.912

Peixe-boi (Trichechus inunguis) $\ldots \ldots \ldots \ldots \quad 121.725$

Queixada ou porcão (Tayassu pecari)..... 198.989

Veado (Mazama sp.) . . . . . . . . . . . . . 222.859

Total

8.804 .637

O perigo de ameaça a uma espécie, está na dependência do valor econômico do seu couro. Esse valor é que vai determinar a intensidade de procura da espécie e, conseqüentemente, seu risco de extinção. Como o salário mínimo no meio rural amazônico é muito baixo e o preço dos produtos de primeira necessidade, muito alto, o "caboclo" se vê forçado a procurar as atividades extrativistas para sobreviver (Tabela 2).

Como a Amazônia não possui mamíferos de grande porte, como os que são freqüentes em outros continentes (África e Ásia), a procura de carne no mercado limita-se a poucas espécies. Historicamente dois animais são ameaçados face à procura de sua carne, estes são o peixe-boi (Trichechus inunguis) (Figura 2) e a tartaruga (Podocnemis expansa). A pre- 
TABELA 2 - Preços de alguns animais silvestres comercializados na Amazônia legal (várias localidades dos Estados do Amazonas, Pará e Mato Grosso).

\begin{tabular}{|c|c|c|c|c|}
\hline Nome local & Espécie & Preço (CR\$/US & & $\begin{array}{c}\% \text { do Sal. mínimo } \\
\text { regional }\end{array}$ \\
\hline Sagui ou Sauim & Saguinus bicolor & $300,00 / 10,00$ & (vivo) & $12,84 \%$ \\
\hline Papagaio & Amazona sp. & $250,00 / 8,50$ & (vivo) & 10,53 \\
\hline Leãozinho & Cebuella pygmaea & $300,00 / 10,00$ & (vivo) & 12,84 \\
\hline Macaco de Cheiro & Saimiri sciureus & $300,00 / 10,00$ & (vivo) & 12,84 \\
\hline Macaco Aranha & Ateles paniscus & $500,00 / 16,50$ & (vivo) & 21,05 \\
\hline Peixe-boi & Trichechus inunguis & $5.000,00 / 165,00$ & (vivo) & 210,9 \\
\hline Onça-pintada & Panthera onca & $2.100,00 / 70,00$ & (couro) & 88,24 \\
\hline Ariranha & Pteronura brasiliensis & $800,00 / 27,00$ & (couro) & 33,68 \\
\hline Lontra & Lutra enutris & $500,00 / 16,50$ & (couro) & 21,05 \\
\hline Gato Maracajá & Felis spp. & $1.200,00 / 40,00$ & (couro) & 50,7 \\
\hline
\end{tabular}

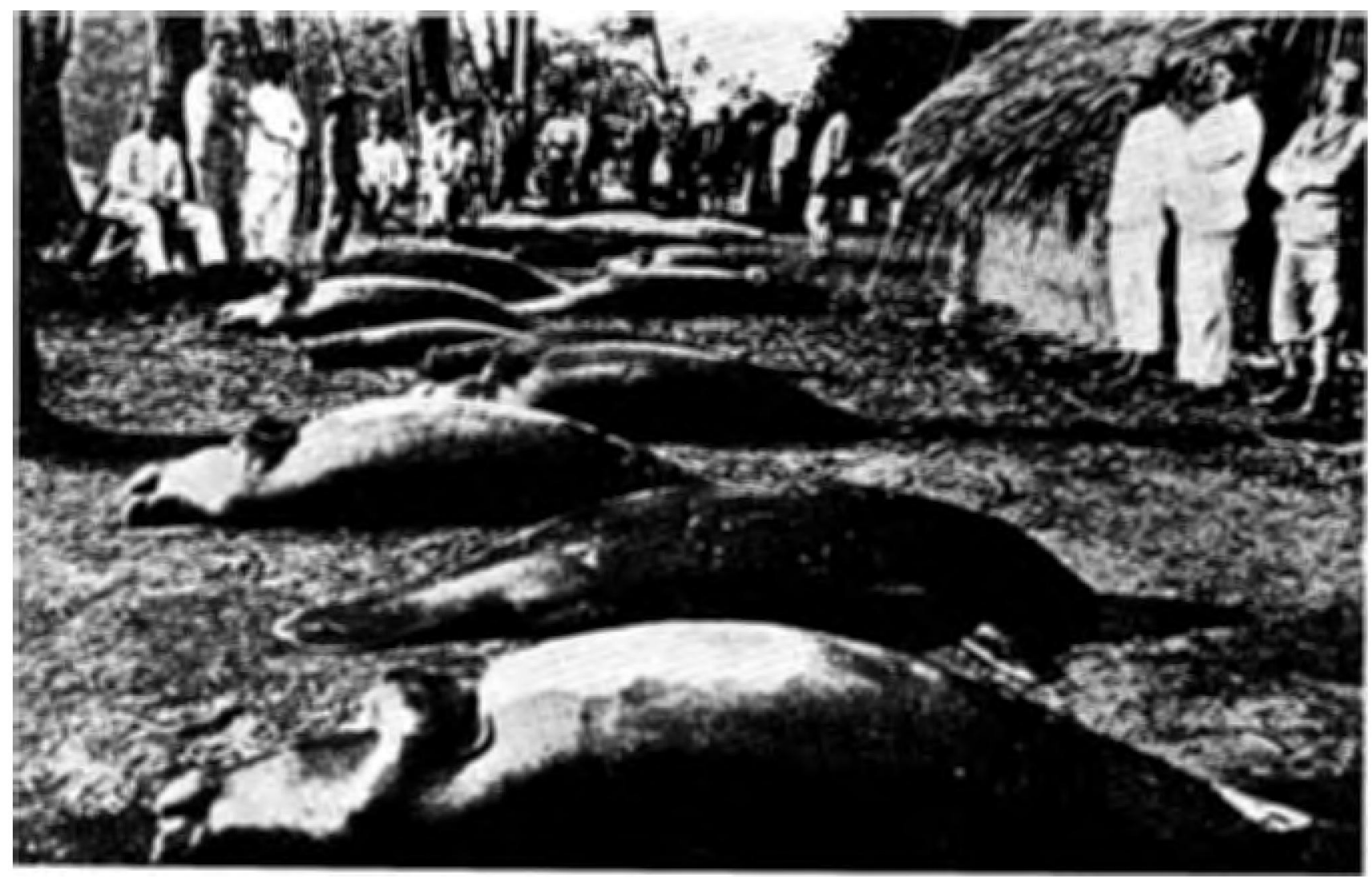

Fig. 2 - A pesca predatória de peixe-boi levou a espécie ao ponte a ser ameaçada de extinção. Aqui está o resultado de um dia de pesca no lago Aiapuá, no rio Purus (foto tirada do trabalho de Rego, 1944).

ferência por esses animais, provavelmente, relaciona-se com o fato de existirem técnicas eficientes para conservação, transporte e esto'cagem de sua carne por um bom tempo Outros animais como a anta, caititu e a queixa- da são também vendidos clandestinamente nos mercados e restaurantes dos centros urbanos como Manaus (Wetterberg et al., 1976) com preços normalmente abaixo dos da carne de gado (Tabela 3 ). 
TABELA 3 - Preços de carne de alguns animais selvagens $\mathrm{e}$ domésticos nos mercados suburbanos da cidade de Manaus (9/1979).

\begin{tabular}{|c|c|}
\hline & $\mathrm{Cr} \$ / \mathrm{kg}$ \\
\hline Capivara (Hydrochaeris hydrochaeris) & 60,00 \\
\hline Peixe-boi (Ttrichechus inunguis) $\ldots$ & 70,00 \\
\hline Queixada ou porcão (Tayassu pecari) & 40,00 \\
\hline Veado (Mazama spp.) . . . . . . . . & 40,00 \\
\hline Tatu (Dasypus spp.) ..... & 30,00 \\
\hline Paca (Dasyprocta agouti) .. & 40,00 \\
\hline Galinha de granja ......... & 85,00 \\
\hline Porco doméstico $\ldots \ldots \ldots \ldots \ldots \ldots$ & 60,00 \\
\hline Carne de gado (equivalente). & 170,00 \\
\hline
\end{tabular}

Pouco se conhece a respeito da comercialização de animais vivos na Amazônia brasileira (Carvalho, 1967), contudo, sabe-se que entre os mamíferos, os primatas são os grupos mais procurados, tendo especial preferência os gêneros Saimiri, Aotus e Saguinus (Kalter et al., 1976).

Com a restrição às importações dos primatas do velho mundo, principalmente os macacos rhesus (Macaca mulata) provenientes da India, houve um aumento considerável na pro. cura dos primatas neotropicais pelos laboratórios de pesquisas e indústrias farmacêuticas (Thorington, 1969).

O comércio de primatas no Brasil nunca se deu em grande escala, já que pelas estatísticas conhecidas, os maiores exportadores cia América do Sul são o Peru e a Colômbia. Nesses países, os locais de maior captura e exportação são Iquitos (PE) e Letícia (CO), cidades bem próximas à fronteira da Amazônia Ocidental brasileira (Coimbra-Filho, 1972; Mittermeier \& Coimbra-Filho, 1977). Somente entre 1961 e 1971, foram exportados de lquitos mais de 330.000 macacos (Grimwood, 1968, Soini, 1972)

\section{CAÇA DE SUBSISTENCIA}

Os indígenas e caboclos da região sempre dependeram da caça e pesca como fontes naturais de proteína animal e outros nutrientes (Pierret, 1967, Gross, 1975; Smith, 1976; Shrimpton, 1977; Shrimpton êt al., 1978; Ayres \& Ay. res, 1979). Esta atividade é mais generalizada que a caça comercial, dependendo principalmente da disponibilidade de cada espécie, época e método de caça empregado (Smith, 1978; Ross, 1978). Algumas espécies são protegidas por tabus alimentares pelo caboclo e o índio, os quais vêm sendo modificados lentamente com a imigração de outras regiões do país e pela falta de outras espécies cinergéticas (Ross, 1978; Smith, 1978).

Como meio de subsistência, essa exploração não constitui atualmente uma ameaça à fauna local. No entanto, se não for observado um esquema racional de ocupação da área, a baixa biomassa de vertebrados da região (Fittkau \& Klinge, 1973) não poderá suportar a intensificação da atividade.

\section{CONSERVAÇÃO E MANEJO DA FAUNA}

MANEJo, Fiscalização E EDUCAÇÃo

Dada a pobreza de informações sobre a biota amazônica, os sistemas de manejo usados nos países desenvolvidos não podem ser aplicados a ela nos dias de hoje. Além deste problema, os sistemas vigentes de fiscalizaçāo não são adequados para a manutenção e a coleta dos dados necessários para avaliar os efeitos da utilização. Das informações biológicas críticas para o manejo de qualquer espécie, deveriamos incluir os seguintes aspectos [Giles, 1969) :

a) dinâmica das populações;

b) uso do espaço e habitat crítico;

c) cronologia da história natural, época de reprodução, sobrevivência da prole, etc.;

d) grau de exploração humana.

Nisnhum vertebrado endêmico da Amazônia chegou a ser estudado a tal ponto que se pudesse conhecer todos estes aspectos da sua biologia, podendo conseqüentemente fazer-se Lim manejo apropriado das populações. A finalidade de manejar alguns elementos da fauna não é simplesmente dar proteção aos animais em fase de extinção mas visa principalmente o prolongamento da sustentabilidade da caça de subsistência: Tentativas de manejo têm sido feitas pelo IBDF, em alguns tabuleiros de desova da tartaruga, com resultados ra- 
zoáveis (Alho et al., 1979), no entanto faltam ainda maiores conhecimentos sobre a biologia da espécie para avaliar o programa.

Apesar de sua grande extensão florestal, a Amazônia brasileira tem um número muito limitado de fiscais. Como por exemplo, o Estado do Amazonas tem apenas 22 fiscais, o que corresponde a 1 fiscal para cada 7 milhões de hectares de floresta. Estes indivíduos são logicamente os responsáveis pela proteção da fauna e flora dessa enorme extensão, o que é um trabalho impossível de ser realizado. A fiscalização torna-se importante se efetivamente levar ao cumprimento das leis do código florestal, especificamente aquelas que dizem respeito à faúna. Ao nível mais específico (parques nacionais, reservas e equivalentes) a fiscalização é crítica para a proteção das unidades de conservação. O tráfico de peles, couros e animais vivos também poderá ser significativamente inibido, através das patrulhas de guardas florestais nas estradas e principalmente nos rios que cruzam a fronteira do país. Nestas regiões fronteiriças deveriam ser estimulados os acordos bilaterais entre os órgãos responsáveis pelo patrimônio biológico do país em questão (Pacto Amazônico).

Paralelamente a esse incremento, faz-se necessária a elevação dos níveis educacionais e salariais, já que a maior freqüência de corrupção nesta profissão, é um reflexo das precárias condições de vida da população. A educação preservacionista pode ser feita através de programas educacionais implantados nos cursos de alfabetização e $10^{\circ}$ grau, com conti nuidade até ao nível superior. Programas sobre a natureza e conservação na televisão, rádios, jornais e revistas poderão contribuir decisivamente para a implantação dessa consciência.

\section{PARQUES NACIONAIS}

As conseqüências das elevadas taxas de desmatamentos anteriormente referidas já começam a se fazer sentir nas alterações climáticas (Salati \& Ribeiro, neste volume) e nos problemas com os níveis d'água dos rios e a ciclagem de nutrientes (Schubart, 1977). Desta maneira as preocupações ao nível de ecos- sistema aumentaram sensivelmente nos últimos 3 anos.

O sistema existente de planejamento dos parques (IBDF, 1979) e estações ecológicas (SEMA, 1977) está bastante atrasado em relação às taxas de desmatamentos. As áreas propostas são, em sua maioria, inadequadas tanto no tamanho, quanto na localização da área a ser protegida e não leva em consideração a imensa diversidade faunística regional. Por exemplo, muito pouca ênfase tem sido dada aos ecossistemas aquáticos.

Os dados mais importantes sobre a área mínima de uma unidade de conservação ainda não são conhecidos. Por exemplo : qual é a área mínima para incluir populações geneticamente viáveis dos animais que ocupam o topo da cadeia alimentar, como a onça-pintada (Panthera onca) ou o gavião real (Harpia harpyja) ?

Para respondermos a problemas deste tipo, é lógico que mais estudos devem ser feitos, no entanto como o tempo necessário para elucidar tais questões é longo, não poderemos deter-nos neles sem que antes sejam tomadas medidas mais abrangentes. Não queremos com isto dizer que estes estudos não devam ser realizados, muito pelo contrário, eles deveriam ser intensificados e os desmatamentos desacelerados, até que se conheça o suficlente para planejar racionalmente as áreas de preservação e exploração não predatória da biota.

A realidade no entanto é outra. Os órgãos uficiais vêm respeitando muito pouco os princípios ecológicos fundamentais, e indiscriminadamente vêm determinando áreas para exploração, com base em objetivos econômicos imediatos.

O sistema brasileiro de parques nacionais, vigente na Amazônia, foi baseado no conceito de refúgios (Wetterberg et al., 1977). Estes refúgios seriam áreas de alto endemismo, formadas por contrações climáticas durante 0 Pleistoceno e que constituiram o centro de dispersão e evolução das espécies. O modelo de parques pelo IBDF consiste numa relação de áreas derivadas da superposição de refúgios determinados para alguns organismos. Os gru. 
pos incluem pássaros (Haffer, 1969; 1974), lagartos (Vanzolini, 1973), duas subfamílias de borboletas (Brown et al., 1974; Brown, 1977) e 4 famílias de plantas (Prance, 1973). Nas áreas onde os refúgios coincidem mais de duas vezes, pelos autores são consideradas prioritá. rias e assim por diante. Este modelo estará criando irremediavelmente um isolamento geo. gráfico sem levar em consideração a variabilidade das raças geográficas nem os ecossistemas aquáticos. Além disso, o número de refúgios aumenta inversamente proporcional ao tamanho do organismo em questão. Assim, por exemplo, o refúgio de uma borboleta da família Nymphalidae não poderá nunca ter o rnesmo tamanho que o de uma anta (Lovejoy, 1979).

Desta proposição, partimos para um modelo mais abrangente, que é compatível com as áreas propostas pelos técnicos do IBDF (Wetterberg et al., 1977; IBDF, 1979) e as subdivisões fitogeográficas (Braga, neste volume). Para que seja realmente representativo da imensa diversidade o sistema de parques deveria incluir áreas biogeográficas distintas, cujos componentes apresentassem diferenças funcionais, morfológicas e genéticas significativas. Alguns autores como Hershkovitz (1963), Fooden (1965), Sick (1967), ÁvilaPires (1974), Hershkovitz (1978) têm chamado a atenção para a importância dos grandes rios como barreiras de isolamento geográfico para os componentes faunísticos da bacia amazônica. Deste modo, propomos um modelo baseado em 12 regiões biogeográficas distintas (Figura 3), no qual os rios funcionam como barreiras de isolamento geográfico. Dentro de cada uma destas áreas propostas, teríamos que proteger os biótopos de maneira que as popu. lações endêmicas fossem genética e ecolog! camente viáveis, selecionando-se, para tal, áreas proporcionais à quantidade da fauna $e$ flora, que eles contêm. Assim $10 \%$ ou mais em áreas contínuas seriam transformados em Parques Nacionais, e outros $10 \%$ seriam divididos em unidades menores de conservação, tais como, Reservas Biológicas, Estações Ecologicas, Santuários e Parques Estaduais.
Para evitar o isolamento e a formação de ilhas genéticas ou refúgios artificiais, deveria haver uma continuidade entre as unidades meroores de cada província biogeográfica e entre os parques nacionais. Estes "cinturões verdes" que permitiriam um fluxo genético entre as populações das espécies de cada uma destas áreas, poderiam ser estabelecidos com base no item b do Artigo 16 do Código Florestal (IBDF), segundo o qual qualquer propriedadt rural deverá sempre deixar $50 \%$ de floresta intocados. Assim, teríamos uma forma de organização entre os proprietários das estruturas fundiárias de maneira que deixassem intocada exatamente a faixa correspondente ao "cintu. rão verde" (Figura 4).

As 12 sub-regiões seriam submetidas a levantamentos sistemáticos para determinar os seguintes parâmetros :

a) situação fundiária, densidade populacional humana e distribuição dos grupos indigenas;

b) ocupação e uso da terra (que poderia ser feito facilmente através de imagens de satélite LANDSAT);

c) revatamento florístico (Projeto Flora);

d) levantamento faunístico (o ainda não existente Projeto Fauna);

e) geomorfologia e geologia;

f) uso potencial da terra (agropecuário $P$ desenvolvimento florestal).

Estes levantamentos poderiam ser desen volvidos por uma equipe de pesquisadores do INPA em conjunto com outras instituições de pesquisa na região.

Torna-se necessário que se faça com urgência os levantamentos referentes aos itens a e b (no prazo de alguns meses) com bases em dados já existentes como as estatísticas cadastrais do INCRA, FIBGE e INPE, de cada uma das sub-regiōes propostas. Deve-se levar em consideração que a política de distribuição das propriedades, favorecendo o estabelecimento de grandes latifúndios (INCRA, 1974: Santos, 1977) pode ocasionar problemas na instalação de reservas florestais onde as tensões fundiárias são grandes como no caso de algu mas áreas propostas. Com a expulsão dos pos- 
seiros de suas propriedades pelas empresas de grande porte, há uma tendência de os mes. mos virem a ocupar as áreas destinadas a estas reservas. No caso amazônico, com a ine. xistência de uma justiça agrária e uma política de distribuição mais uniforme de terra entre as populações marginalizadas, estes conflitos são muito freqüentes.

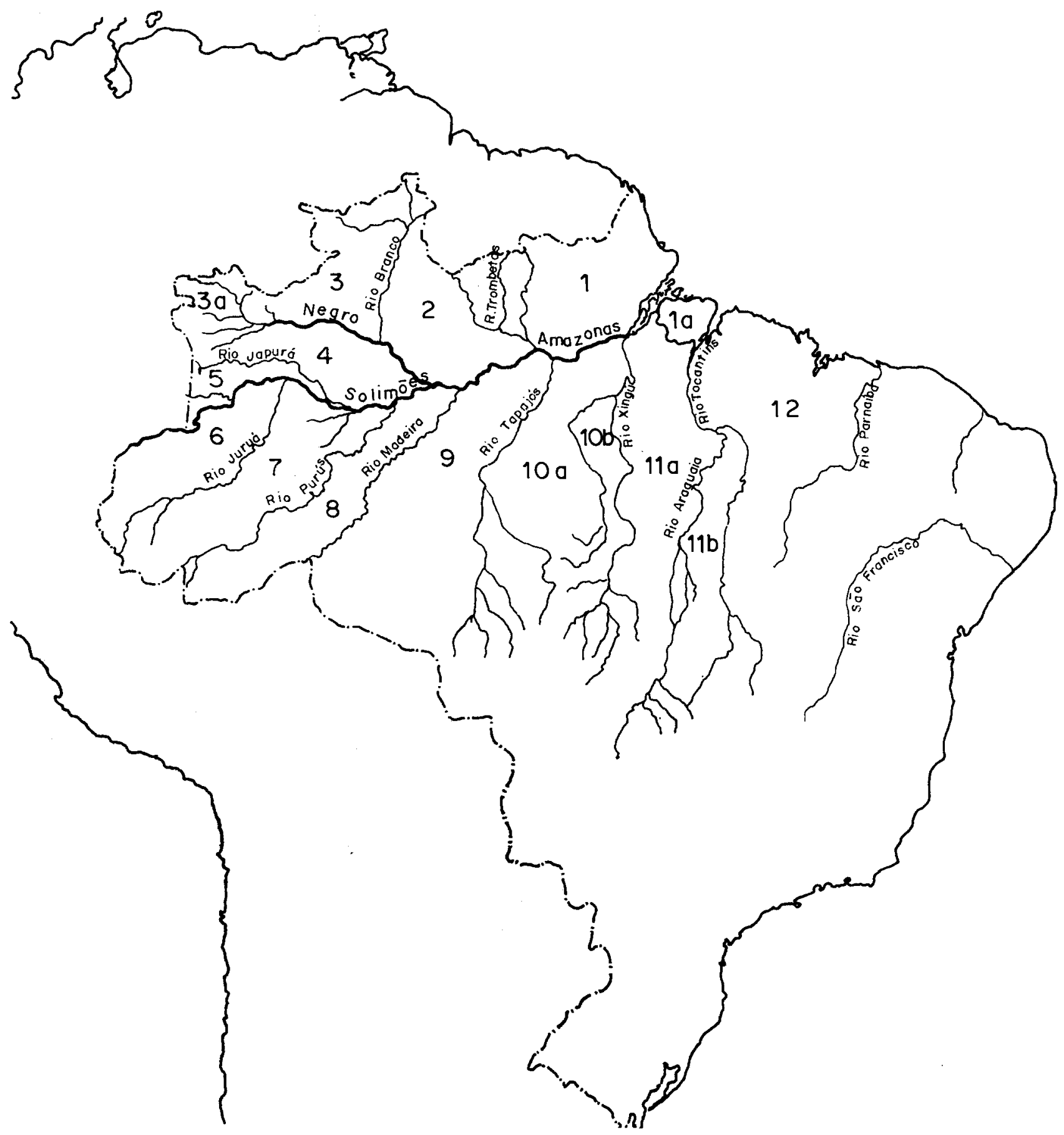

Fig. 3 - Definição de 12 grandes regiōes, delimitadas pelos prineipais rios, para fins de preservação da biota. Em cada região, $10 \%$ ou mais em área contínua seriam transformadas em Parques Nacionais; outros $10 \%$ seriam divididos em outras unidades de preservação, tais como, Reservas Biológicas, Estações Ecológicas, Santuários e Parques Estaduais. 


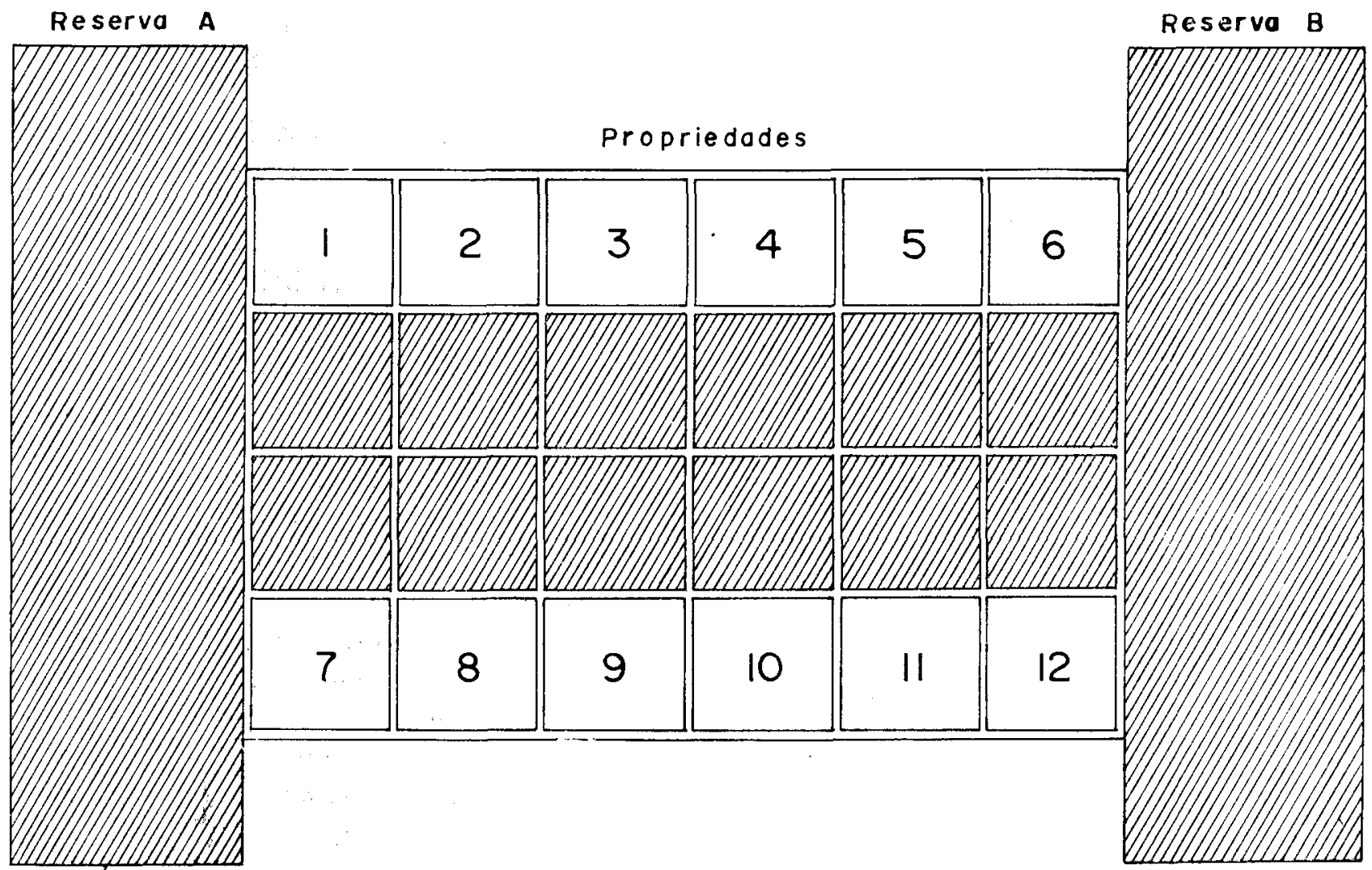

Fig. 4 - Modelo esquemático para corredores entre Parques Nacionais e ou as demais unidades de conservação na Amazônia brasileira.

A partir do conhecimento sobre as estatísticas atuais de ocupação, potencial e planos futuros para a utilização de cada uma destas subregiões, poderemos detectar quais as áreas prioritárias (levando em conta a ocupação) para os levantamentos mais minuciosos. A medida que cada biorregião for cuidadosamente analisada nos parâmetros mencionados, as áreas correspondentes à conservação deverão ser imediatamente discriminadas e demarcadas.

Todos os aspectos mencionados acima são da mais alta importância e devem ser levados adiante o mais breve possível. É melhor que tais providências sejam tomadas logo e a nível de ecossistemas, e não ficarmos somente tentando remediar com programas de salvação de determinadas espécies ameaçadas de extinção.

\section{CRIAÇÃo EM CATIVEIRO}

Têm sido feitas várias propostas de criação de animais silvestres e lacustres em cativeiro para fins econômicos e assim diminuir a saída dos estoques naturais. Até hoje não existe nenhum programa ao nível experimental em andamento na Amazônia brasileira, contudo o projeto CECAM do IBDF está sendo desenvolvido. O programa de piscicultura tropical já está sendo implantado em nível experimental no INPA (St. Paul \& Bayley, neste volume). Os objetivos dos programas de criação em cativeiro podem ser fundamentalmente econômicos e/ou de reintrodução de espécies ameaçadas em seus habitats originais. No primeiro caso, nossos conhecimentos precários sobre a biologia reprodutiva, de crescimento e nutricional, resultam numa superestimação da capacidade de desfrute das criações. No sentido 
de criar animais para serem reintroduzic'os em seus habitats naturais, a criação em cativeiro só será recomendável quando for possivel proteger a fauna pelo sistema de parques mencionados anteriormente. Também, o sistema de criadouros particulares, se não for bem fiscalizado, poderá trazer problemas para a fauna silvestre, pois se tem verificado que geral. mente estes servem apenas como um dispositivo para burlar a lei que próbe a comercialização de animais silvestres, já que muitos utilizam animais capturados na natureza, como parte de sua produção.

Para concluir, a criação em cativeiro não está ainda no estado de produção econômica dada a falta de maiores conhecimentos sobre a biologia de cada espécie, e não pode ser considerada de grande importância para a conservação até que um sistema de unidades de conservação esteja funcionando como o tal. No caso da criação econômica, há uma exceção: existe uma boa base científica para o manejo da capivara, em cativeiro, adquiricio na Venezuela (Ojasti \& Padilha 1972; Ojasti, 1973; Gonzalez \& Parra, 1975).

\section{AS ESPÉCIES AMEAÇADAS}

O problema das espécies ameaçadas de desaparecimento, vêm preocupando, com o passar dos anos, o mundo contemporâneo. Antes do ano 1600 , estima-se que as taxas de extinção naturais eram de uma espécie a cada 1000 anos. De 1600 até 1950 estas taxas elevaram-se ao ponto de haver uma extinção a cada 10 anos. De 1950 para os dias atuais desaparece pelo menos uma espécie a cada ano (Myers, 1976). Na Amazônia, provavelmente ainda não chegamos a este estágio, todavia não estamos muito longe do dia em que começarão a desaparecer as primeiras de nossas espécies. Em 1977, durante o primeiro encontro das entidades conservacionistas, sobre o Comércio Internacional das Espécies da Fauna e Flora ameaçada de extinção, já havia na lista oficial da CITES algumas espécies da fau. na amazônica. Eram 14 mamíferos, 2 aves e 4 répteis (IUCN, 1977). Aqui, organizamos uma nova lista que acrescenta mais algumas espé- cies amazônicas, comentando de maneira geral os problemas de cada grupo que achamos que devem ser tratados com maior atenção. Esta lista contém 20 espécies de mamíferos, 5 de aves e 3 de répteis. Utilizamos as mesmas categorias do "Red Data Book" (IUCN, 1974), para avaliar a situação de cada uma das espécies constituintes da lista (Tabela 4):

a) ameaçadas - espécies em perigo de extinção são aquelas cuja sobrevivência é im. possível se as causas de sua dimiuição continuarem a operar. Incluídas as espécies cujos números foram reduzidos a um nível crítico ou cujos habitats foram tão drasticamente reduzidos que elas estão em perigo imediato de extinção;

b) vulneráveis ( $V$ ) - espécies que provavelmente estão indo em direção à categoria $(A)$ no futuro próximo, se as causas de sua diminuição populacional continuarem a operar;

c) raras (R) - são aquelas com pequenas populações mundiais que não estão no presente em perigo, mas estão em risco, por causa de sua distribuição restrita ou estão esparsamente distribuídas em uma área mais extensa;

d) indeterminadas (1) - são aquelas que se suspeita estarem em uma das três primeiras categorias, mas não há informações suficientes disponíveis.

\section{ALGUNS COMENTARIOS SOBRE ESPÉCIES AMAZONNICAS POTENCIALMENTE AMEAÇADAS DE EXTINÇÃO}

\section{MAMMALIA}

\section{Ordem STRENIA}

O peixe-boi da Amazônia (Trichechus inunguis) é um animal historicamente caçado desde o século XVII. Sua distribuição inclui as águas da bacia amazônica (rios e lagos) até as primeiras corredeiras de cada afluente do rio Amazonas (Pereira, 1944: Rego, 1944; Vieira, 1955; Veríssimo, 1970).

O peixe-boi é o único mamífero herbivoro, totalmente aquático, nas águas da bacia amazônica, onde se alimenta de macrófitas aquáticas (ex : capins, murirú, aguapé, etc.) (Best a, 
TABELA 4 - Lista das espécies da fauna amazônica potencialmente ameaçadas de extínção. (A) Ameaçada; (V) Vulnerável; (R) Rara; (1) Situação Indeterminada. (1) Destruiçāo do habitat; (2) Comercialização da pele ou carne; (3) Caça de Subsistência.

\begin{tabular}{|c|c|c|c|c|}
\hline Classe/Ordem & Espécies & Nome Popular & $\begin{array}{l}\text { Situação } \\
\text { Atual }\end{array}$ & $\begin{array}{l}\text { Ameaças } \\
\text { Potenciais }\end{array}$ \\
\hline MAMMALIA/SIRENIA & Trichechus inunglīs & Peixe-boi & A & $2-3$ \\
\hline MAMMALIA/CARNÍVORA & Panthera onca & Onça-pintada & V & $2-1$ \\
\hline MAMMALIA/CARNIVORA & Felis $\mathrm{spp}$ & Maracajás & V & $2-1$ \\
\hline MAMMALIA/CARNIVORA & Atelocynus microtis & $\begin{array}{l}\text { Cachcrro-do-mato } \\
\text { de orelha curta }\end{array}$ & $\mathrm{R}$ & 1 \\
\hline MAMMALIA/CARNIVORA & Spheothus venaticus & Cachorro-do-vinagre & $\mathrm{R}$ & 1 \\
\hline MAMMALIA/CARNIVORA & Pteronura brasiliensis & Ariranha & A & $2-1$ \\
\hline MAMMALIA/CARNIVORA & Lutra enudris & Lontra & V & $2-1$ \\
\hline MAMMALIA/EDENTATA & Priodonteus giganteus & Tatu-canastra & V & $1-3$ \\
\hline MAMMALIA/EDENTATA & Myrmecophaga tridactyla & Tamanduá-bandeira & V & 1 \\
\hline MAMMALIA/PRIMATA & Ateles paniscus & Coatá, Macaco-aranha & V & $1-3$ \\
\hline MAMMALIA/PRIMATA & Ateles belzebuth & Coatá, Macaco-aranha & V & $1-3$ \\
\hline MAMMALIA/PRIMATA & Lagothrix lagothricha & Macaco barrigudo & V & $1-3$ \\
\hline MAMMALIA/PRIMATA & Cacajao calvus calvus & Uacari branco & V & $3-1$ \\
\hline MAMMALIA/PRIMATA & Cacajao melanocephalus & Uacari cabeça preta & V & $3-1$ \\
\hline MAMMALIA/PRIMATA & Chiropotes albinasus & Cuxiú-de-nariz vermelho & V & $1-3$ \\
\hline MAMMALIA/PRIMATA & Chiropotes satanas satanas & Cuxiú preto & $A$ & $1-3$ \\
\hline MAMMALIA/PRIMATA & Saguinus imperator & Bigode, Saguí de bigode & V & 1 \\
\hline MAMMALIA/PRIMATA & Saguinus bicolor & Saguí de colar, Sauim & $A$ & 1 \\
\hline MAMMALIA/PRIMATA & Callimico goeldi & Callimico & $\mathrm{R}$ & $1-2$ \\
\hline AVES/FALCONIFORMES & Harpia harpyja & Gavião real ou Uiraçu & $\mathrm{R}$ & 1 \\
\hline AVES/FALCONIFORMES & Morphus guianensis & Uiraçu menor & $\mathrm{R}$ & 1 \\
\hline AVES/GALLIFORMES & Crax fasciolata pinima & Mutum pinima & A & $1-3$ \\
\hline AVES/PASSERIFORMES & Haematoderus militaris & Anambé vermelho & $\mathrm{R}$ & 1 \\
\hline AVES/PSITTACIFORMES & Aratinga guarouba & Ararajuba & V & $1-2$ \\
\hline REPTILIA/CHELONIA & Podocnemis expansa & Tartaruga & V & $2-3$ \\
\hline REPTILIA/CROCODILIA & Melanosuchus niger & Jacaré-açu & A & 2 \\
\hline REPTILIA/CROCODILIA & Caiman crocodilus & Jacaretinga & V & 2 \\
\hline
\end{tabular}

no prelo). Quando adulto, atinge até 3 metros de comprimento chegando a pesar entre 400 . $500 \mathrm{~kg}$. A fêmea tem um filhote de cada vez, a cada três anos, cuja gestação e desmame dura aproximadamente 12 e 18 meses respectivamente (Hartman, 1968; Dekker, 1978). Os filhotes nascem durante a enchente, quando há maior produção de plantas aquáticas (Best b, no prelo) .

É considerado atualmente pelo IBDF e IUCN como espécie ameaçada de extinção dada a sua alta exploração a algumas décadas 
atrás. A maior predação da espécie ocorreu entre 1935 e 1954, quando foram exportados, de acordo com as estimativas, aproximadamente 200.000 couros (Mendes, 1938; Pereira, 1944). Mais recentemente houve grandes matanças nos lagos de Coari, Tefé e Manacapuru durante a grande seca de 1963, quando os boiadouros e poços secaram muito deixando os animais extremamente vulneráveis aos pescadores. O peixe-boi está protegido por lei desde 1967 (IBDF, 1967), mas com a fiscalização deficiente, sua pesca é feita ern toda Amazònia dada sua carne saborosa.

\section{Recomendações :}

a) Aumentar a fiscalização nas áreas conhecidas como boiadouros e poços e aos paranás de arribação (onde os peixesboi ficam empoçados dı.ırante a estaçào seca) especialmente nos anos que o Amazonas e tributários baixam mais que o normal.

b) Escolher áreas com populações razoáveis do peixe-boi para serem protegidas como unidades de conservação.

c) Continuar as pesquisas em andamento para melhor proteger e manejar a espécie.

\section{Ordem CARNÍVORA}

Os animais pertencentes a esta ordem são ameaçados por três razões que, em ordem de importância são as seguintes :

a) comercialização de peles;

b) destruição dos habitats naturais;

c) problema da predação de animais domésticos, principalmente o gado.

Como estes animais são carnívoros, e ocupam o ponto mais alto da cadeia alimentar, estes exigem uma área bastante grande para sobreviver, fato que entra imediatamente em conflito com os interesses de desenvolvimento agropecuário e florestal da Amazônia.

A onça-pintada (Panthera onca) está distribuída em toda a bacia amazônica (Cabrera, 1957), é o maior e mais espetacular de todos os gatos neotropicais e o adulto pode pesar até $140 \mathrm{~kg}$ (Coimbra-Filho, 1972). É muito procurado por sua pele, que é utilizada na con- fecção de casacos em outros países. Somente de Belém em 1969, foram exportados cerca de $2.115 \mathrm{~kg}$ de peles desta espécie (Dougthy \& Myers, 1971] e aproximadamente 11.000 peles foram exportadas do Estado do Amazonas em 9 anos, entre 1950 e 1965 (Carvalho, 1967).

$\mathrm{O}$ valor do couro de onça-pintada no interior do Amazonas está entre 1.800 a 2.500 cruzeiros (60 a 82 dólares) e recentemente vários couros foram encontrados numa área perto do Japurá, sendo exportados pela fronteira colombiana. Em alguns locais como o sul do Pará, tomado pelos grandes projetos agropecuários, as populaçōes de onça provavelmente estão em sensível declínio.

Não sabemos ainda qual é a área mínima necessária para sustentar uma população geneticamente viável da espécie, mas acredıtase que é muito grande e tem que incluir simultaneamente populações razoáveis de presas para as onças. Se estas populações de animais predados não existirem em quantidades que sejam suficientes para manter suas populações, a onça-pintada procurará outras fontes de alimento, tais como animais domésticos e então passará a ser uma ameaça para os criadores de bovinos e bubalinos.

Os gatos maracajás, jaguatiricas, etc. (Felis spp), formam um complexo de Felidae menores que, como a onça-pintada, são muito procurados por suas peles. Isto, somado às destruições dos habitats naturais das espécies, têm reduzido bastante as populações destas espécies. Somente do Brasil, foram exportadas em 1969, cerca de 81.226 peles destes gatos sendo a maioria proveniente do Estado do Pará (Doughty \& Myers, 1971) e seus couros têm valor relativamente alto $(1.200,00$ cruzeiros $=40$ dólares], quase igual ao da onça-pintada.

Estes animais, por possuirem menor porte e ter um ciclo reprodutivo mais rápido, têm as populações nativas geralmente maiores que as da onça-pintada, mas não podemos dizer qual é o grau de ameaça a que as populações do grupo são mais susceptíveis.

A ariranha (Pteronura brasiliensis) está distribuída provavelmente em todos os rios da bacia amazônica (Vieira, 1955; Cabrera, 1957). 
E, provavelmente, dentre os componentes da mastofauna da região, aquele que se encontra em maior grau de ameaça de extinção. Tanto seu couro como o animal vivo têm altas cotações no mercado internacional. Como a ariranha é um animal de hábitos diurnos, aquáticos e anda, muitas vezes, em grupos familiares extensos, fazendo muito barulho, ficam susceptíveis à caça. Não é raro um caçador abater a família inteira. A destruição das florestas ao longo dos rios e o aumento do movimento das embarcações são fatores igualmente importantes para o desaparecimento da espécie. Com a recente abertura de rodovias no sul da Amazônia (Exemplo : AR-01) vão acabar com as razoáveis populações existentes naquela região, nos rios do Sangue, Juruena, Aripuanã e Canumã.

As lontras (Lutra enudris) encontram-se em situação semelhante às das ariranhas, embora suas populações pareçam ser maiores e o valor comercial de sua pele mais baixo no mercado internacional.

Os cachorros-do-mato de orelha curta e vinagre (Atelocynus microtis e Speothus venaticus), o primeiro endêmico da Amazônia, são raros e muito pouco conhecidos mesmo para habitantes da região. O cachorro-do-mato de orelha curta está distribuído em toda a Amazônia desde o nível do mar até 1000 metros de aititude. Sua pelagem sugere que estão adaptados a locais com alta pluviosidade (Hershkovitz, 1961). O cachorro-do-mato vinagre tem distribuição mais extensa que o anterior, é aparentemente noturno e costuma caçar em grupo. Nada muito bem e vive nas matas primárias de terra firme ou formações de cerrados (Walker et al., 1968).

Embora nenhum dos dois cachorros-do-mato sejam caçados em razão de sua pele ou de sua carne, suas populações devem estar sofrendo reduções com a destruição dos ambientes naturais. Até que estes animais sejam melhor conhecidos com relação à sua biologia, ecologia e distribuição teremos que considerá-los vulneráveis, em face da destruição da floresta amazônica. No Brasil, todos estes animais da ordem Carnívora citados, estão protegidos por lei.

\section{Recomendações :}

a) Aumentar a fiscalização sobre os que estimulam a perseguição das espécies que são caçadas por causa da sua pele, principalmente na Amazônia ocidental, por onde estão sendo exportados atualmente.

b) Estudos ecológicos para determinar que condições devem ser fornecidas nos Parques e Reservas, para assegurar a sobrevivência das espécies.

\section{Ordem EDENTATA}

o tatu-canastra (Priodontes giganteus), é o maior de todos os animais componentes desta ordem e pode atingir até $60 \mathrm{~kg}$ de peso (Coimbra-Filho, 1972). Este animal é perseguido em alguns locais, dada sua carne, além de outros tatus. É noturno e normalmente muito raro, mas deixa vestígios, por exemplo, suas tocas que são facilmente perceptíveis tornando-o vulnerável ao caçador. Tem valor muito alto no mercado internacional quando é apanhado vivo. A biologia da espécie ainda é muito pouco conhecida.

O tamanduá-bandeira Myrmecophaga tridactyla), é mais conhecido como um animal dos campos, no entanto, ele existe em toda a Amazônia, na floresta tropical úmida, onde provavelmente a densidade populacional é mais baixa, podendo ser considerado um animal raro, sujeito à vulnerabilidade das destruições florestais, pois tem um alcance territorial de aproximadamente 2.500 hectares, que está relacionado com a disponibilidade dos formigueiros (Montgomery \& Lubin, 1977).

\section{Recomendações :}
a) Estudos dos parâmetros biológicos críti- cos das espécies.
b) Localização de áreas adequadas para a proteção das mesmas.

\section{Ordem PRIMATES}

Basicamente, 2 fatos são os responsáveis pela diminuição das populações de primatas na Amazônia brasileira : a destruição dos habitats e a caça de subsistência. O último é 
decorrente do primeiro, pois com a diminuição das populações de animais de maior porte (anta, queixada, capivara, etc.), por causa do desmatamento, os caboclos passam a abater macacos de porte maior como fonte de proteína animal. A captura de animais vivos para exportação e uso em pesquisas biomédicas já atingiu há alguns anos as populações vizinhas da fronteira da Amazônia ocidental, mas não podemos considerar como uma ameaça potencial.

Dentre as 50 espécies existentes neotropicais, 30 ocorrem na região. Aqui consideraremos as 9 que estão com maiores problemas pelos motivos acima expostos.

O uacari-branco (Cacajao calvus calvus), tem uma distribuição muito restrita numa área entre o rio Solimões, o rio Japurá e o Auatí-paraná, no alto da bacia amazônica (Mittermeier \& Coimbra-Filho, 1977). Como a área de ocorrência geográfica é relativamente pequena, qualquer alteração do habitat poderá trazer problemas para esta subespécie. O uacari de cabeça preta (Cacajao melanocephalus) ocorre entre o rio Negro e o rio Japurá em populações esparsamente distribuídas, cuja biologia pouco se sabe ainda (Hernandez-Camacho \& Looper, 1976; Napier, 1976). São muito caçados na Amazônia brasileira, principalmente para servirem como isca para pesca de tartarugas ou em armadilhas para captura de gatos selvagens (IVittermeier \& Coimbra-Filho, 1977).

Os cuxiús (Chiropotes spp.) bem como os outros macacos maiores são bastante caçados para a alımentação humana e com sua cauda são fabricados espanadores que são vendı́os nas lojas de artesanato dos grandes centros urbanos (Ayres, 1977).

Estes animais andam em grupos relativamente grandes, 20-30 animais, podendo assim, com certa facilidade serem observados pelos caçadores. Eles têm uma dieta muito especial (são predadores de semente) em comparação com os primatas neotropicais, o que resulta numa área mais ampla para a viabilidade de um grupo e densidades relativamente baixas (Ayres, 1977). O potencial reprodutivo é baixo, eles têm apenas um filhote de cada gestação, que dura quase 6 meses (Hill, 1960; Hick:
1968). O cuxiú-de-nariz vermelho (Chiropotes albinasus) tem uma distribuição muito ampla entre os rios Xingu e Madeira (Napier, 1976) no entanto, a densidade baixa e o grande número de projetos que estão sendo implantados na área põe em risco a espécie. O cuxiú preto (Chiropotes satanas satanas) (Figura 5) é uma das espécies mais problemáticas visto que sua ocorrência geográfica está limitada à região entre o rio Xingu e a pré-amazônia maranhense, local com densidade demográfica humana alta e onde estão instaladas maior número de empresas agropecuárias.

Os coatás e os macacos barrigudos (Ateles belzebuth, Ateles paniscus e Lagothrix lagothricha), da sub-família dos Atelineos, necessitam também de uma área relativamente grande pa

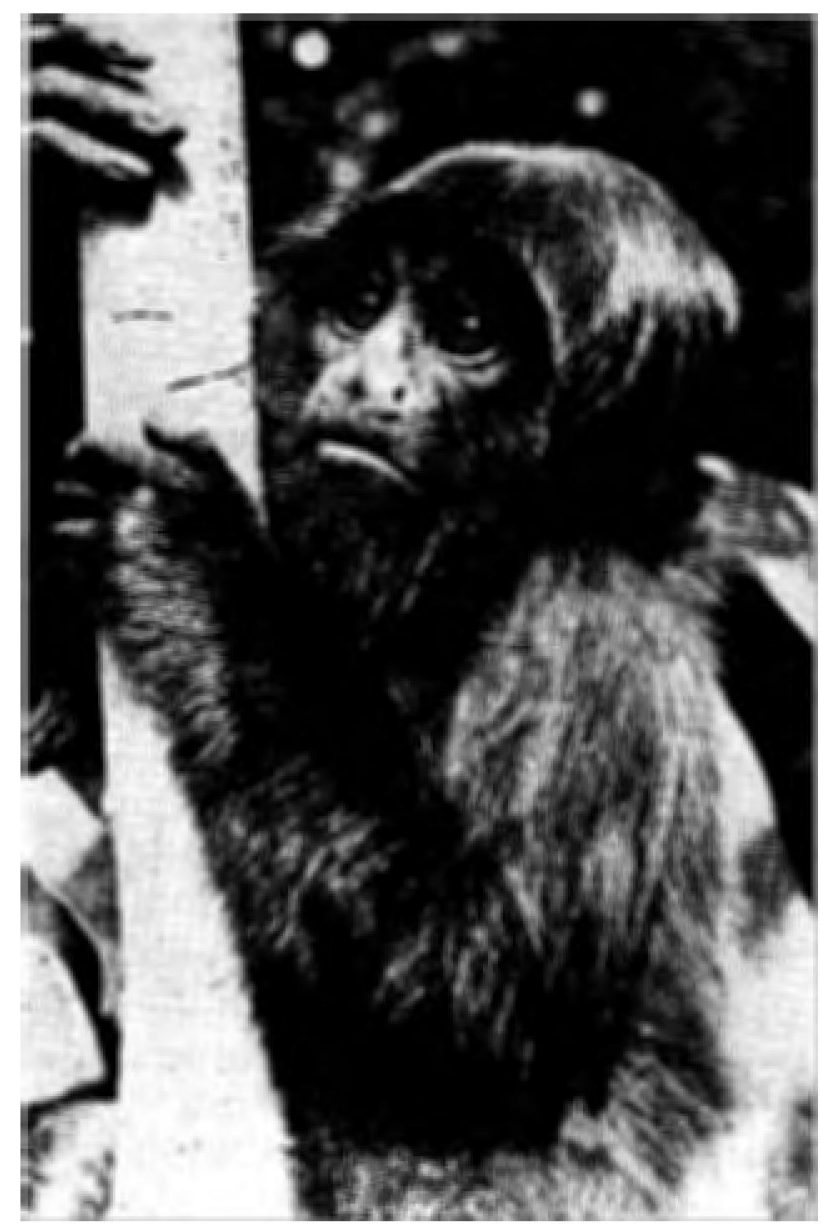

Fig 5 - O cuxiú-preto (Chiropotes satanas satanas) está sendo considerado uma das espécies mais ameaçadas na Amazônia brasileira devido à destruição dos habitats naturais, no sudeste do Pará. 
ra sobreviver (320 hectares para o coatá, fo: encontrada por Klein \& Klein, 1973). Pesam de 5 até $9 \mathrm{~kg}$ (Napier \& Napier, 1967) e por isto são bastante caçados (Ayres \& Ayres, 1979) em sua área de ocorrência geográfica.

O callimico (Callimico goeldi) o único representante da família Callimiconidae é ainda pouco conhecido em relação à sua distribuição. Éstudo recente (Pook \& Pook, 1979) revela que o callimico possui densidade de $0.5-2.0$ indivíduos $/ \mathrm{km}^{2}$, sendo estas populações concentradas em grupos localizados com cerca de 6 nimais. Como estes têm uma cotação muito alta no mercado internacional de zoológicos, sua captura em alta escala, como vinha ocor rendo no rio Acre (Pook \& Pook, 1979), pode agravar as populações da espécie, já com problemas em relação aos desmatamentos inten. sivos.

Entre os primatas menores (Callithrichidae), pouco se sabe sobre o saguí (Saguinus imperator) que ocorre no sudeste da Amazônia brasileira (Napier, 1976), com distribuição relativamente restrita à área que está sendo tomada pelos grandes projetos agropecuários.

O sauim, da região de Manaus (Saguinus bicolor bicolor), possui também uma distribuição mal conhecida (Hershkovitz, 1978. Aparentemente, está limitada às proximidades de Manaus, na área de influência da SUFRAMA e pode ser considerada em declínio, apesar de sobreviverem em matas secundárias, por diminuição considerável do habitat, nos últimos 12 anos.

\section{Recomendações :}

a) Fazer levantamentos sistemáticos das populações de primatas na Amazônia pa. ra determinar as áreas potenciais para a proteção das espécies.

b) Incentivar os estudos relativos aos Pithecinae (principalmente Cacajao spp.) e Lagothrix lagothricha, sobre os quais quase nada se conhece.

c) Quanto ao Cacajao c. calvus, estabelecer um Parque Nacional em sua restrita área de ocorrência geográfica. O Chiro. potes s. satanas ainda é encontrado ao sul dos municípios de Ourém e Capitão
Poço (PA), área que deveria ser também protegida urgentemente, dados os altos índices de ocupação na área da bacia dos rios Capim e Guamá.

d) Aumentar a fiscalização nas fronteiras para evitar a exportação de animais vivos.

\section{AVES}

As aves parecem estar menos ameaçadas, até certo ponto por falta de pesquisas sobre sua distribuição e dinâmica de suas populações, sendo que as espécies de valor econômico mais alto são perceptíveis a este respeito. Os pássaros aqui tratados, dentre os conhecidos, podem ser considerados como os mais ameaçados e a lista ainda está bastante incompleta.

O gavião real (Harpia harpyja) e o uiraçumenor (Morphnus guianensis) as nossas maiores aves raptoriais, estão, como a onça-pinta$\mathrm{da}$, no ponto mais alto da cadeia alimentar, comendo principalmente mamíferos arbóreos como macacos e preguiças (Fawler \& Cope, 1964). Por possuírem um alcance territorial muito grande estão ameaçadas pela destruição dos habitats e das presas naturais. São considerados animais raros (Sick, 1972).

O mutum pinima (Crax fasciolata pinima) foi considerado extinto durante muitos anos Vaurie, 1968) porém a subespécie ainda vive no leste do Tocantins até o Maranhão hileano apesar dos desmatamentos intensivos e da caça pelas populações locais (Novaes, 1978).

A anambé escarlate (Haematoderus militaris] é uma ave quase lendária por não ser conhecido ainda nada sobre o comportamento, e por nunca ter sido muito freqüente (Novaes, com. pessoal). Sua existência no leste do Pará está ameaçada pelas devastações intensas na área de influência da Belém-Brasília (Sick, 1972). Possivelmente ainda existem populações da espécie ao sul de Ourém (PA) nas proximidades da vila Arauaí (Novaes, com. pessoal).

A ararajuba (Aratinga guarouba) um dos mais belos papagaios do Amazonas, devido a sua coloração amarelo vivo, cuja distribuição vai desde a hiléia pré-maranhense até o rio 
Tapajós, com algumas populações no Parque Nacional da Amazônia (Oren, com. pessoal, Foeshaw \& Cooper, 1973). São normalmente raros e muito valorizados no mercado internacional, correm certo risco pois grande parte de sua área de ocorrência está localizada no leste amazônico, atualmente bastante danificado.

\section{Recomendações :}

a) Intensificar os estudos sobre a biologia e distribuição das espécies.

b) Estabelecimento de alguma unidade de conservação à leste do rio Tocantins para proteger principalmente a Aratinga guarouba, Crax fasciolata pinima e Haematoderus militaris.

\section{RÉPTEIS}

Três espécies de répteis amazônicos contribuíram significativamente para a economia extrativista da Amazônia brasileira : o jacaréaçu (Melanosuchus niger), o maior de nossos jacarés, seguido em tamanho pelo jacaretinga (Caiman crocodilus). O primeiro foi, e ainda é, perseguido principalmente por causa do seu couro. A tararuga (P. expansa) é ainda bem conhecida por sua carne saborosa e sua banha para a fabricação de cosméticos.

\section{Ordem CROCODILIA}

(por William Magnussonj

Ocorrem 4 espécies de jacarés na Amazônia, o Caiman crocodilus, o Paleosuchus palpebrosus, P. trigonatus e M. niger (Carvalho, 1951). O gênero Paleosuchus não tem valor comercial no mercado de peles (Vanzolini, 1972; Medem, 1971a) mas, hoje em dia está sendo procurado pela sua carne juntamente com as outras espécies. O jacaretinga tem sido caçado intensivamente nos últimos anos em razão da sua pele, cujo valor comercial é menor que o de Melanosuchus, desde que houve um declínio considerável das populações do jacaré-açu pela caça intensiva. É considerado como vulnerável, mas não está em perigo imediato de extinção (observações pessoais; Vanzolini \& Gomes, 1979). O jacaretinga foi estudado intensivamente nos llanos venezuelanos (Staton \& Dixon, 1975; 1977), contudo, muito pouco se sabe sobre sua biologia na Amazônia. O jacaré-açu foi pouco estudado e muito explorado (Medem 1963, 1971b; Nicéforo, 1955). É considerado como uma das espécies de jacarés mais ameaçadas na região neotropical. Nada se sabe sobre a biologia de $M$. niger exceto algumas observações superficiais. Esta espécie está distribuída em toda Amazônia, mas seus requerimentos básicos de habitat são desconhecidos e pode ser difícil determiná-los, agora que suas densidades foram alteradas pela caça. A única informação que temos sobre a situação da espécie é que suas peles formam uma pequena parte da comercialização ilegal. daí seu alto valor comercial. Obviamente, o número de indivíduos foi largamente reduzido em comparação aos citados por Bates (1863) e Hagmann (1909).

\section{Recomendações :}

a) Levantamentos sistemáticos feitos imediatamente para determinar a situação atual das populações.

b) Proteger as espécies com a criação de reservas especiais que contenham populações razoáveis e habitat adequado.

c) Aumentar a fiscalização nas fronteiras para diminuir a saída de couros e carne seca.

\section{Ordem CHELONIA}

Quase todos os quelônios amazônicos são perseguidos desde o tempo em que chegaram aqui os primeiros colonizadores. A tartaruga (P. expansa) que pode alcançar até $82 \mathrm{~cm}$ de comprimento, (Alho et al., 1979) é o maior dos quelônios amazônicos, e aquele que sofre a maior predação (Mittermeier, 1978; Smith, 1974, 1979). A tartaruga é vendida a preços muito altos nos grandes centros urbanos. O método mais comum é capturar as fêmeas no tabuleiro de desova, onde o coletor poderá apanhar os ovos além das fêmeas. Como a tartaruga desova em tabuleiros específicos e em grandes grupos, ela está particularmente ameaçada. Os outros quelônios de porte menor como o tracajá ( $P$. unifilis), a irapuca ( $P$. cayennenesis), cabeçuda ( $P$. dumeriliana), 0 iaçá ( $P$. sextuberculata) e o muçuã (Kinosternum scorpioides) também são muito perseguidos. 
O IBDF está protegendo alguns tabuleiros de desova da espécie. Os indivíduos são retirados quando nascem e posteriormente são li. berados em outros lagos próximos. Com a proteção, está havendo um aumento no número de adultos nas praias de desova, no entanto, este aumento se deve ao fato de haver menor distúrbios nestes tabuleiros, pois não há tem. po suficiente para falar em aumento dos adultos reprodutivos.

Nada se sabe sobre o efeito de retirar os recém-nascidos e mudá-los para outros locais. Mesmo que isto aumente a sobrevivência da prole face a predação, do que também não há provas, não poderemos avaliar sobre que processos estão envolvidos para determinar o local de postura destes indivíduos e a localizacão dos tabuleiros (Granda \& Maxwell, 1978).

\section{Recomendações :}

a) Intensificar os estudos relativos a biologia das espécies (curvas de sobrevivência, processo de escolha do local de desova, etc.).

b) Aumentar o número de tabuleiros protegidos, em região diversas.

\section{BIBLIOGRAFIA}

almo, C. J. R.; Carval.ho, A. G. \& Padua, L. F. M.

1979 - Ecologia da tartaruga da Amazônia e avaliação de seu manejo na reserva biológica do Trombetas. Brasil Florestal, 9 (38): 29-47.

AMADON, D.

1973 - Birds of the Congo and Amazon Forest : A Comparison. In: Tropical Forest Ecosystems in Africa and South America: A Comparative Review. Ed. by Institution Press, Was. hington, D. C. p. 267-277.

Ávila-PiRes, F. D.

1974 - Caracterização zoogeográfica da província amazónica. Il. A família Callithrichidae e a zoogeografia amazônica. An. Acad. Brasil. Ciênc., 46 (1): 159-185.

AYRES, J. M.

1977 - Situação atual da área de ocorrência do Cuxiú (Chiropotes satanas satanas - Hoff., 1807). Relatório para IUCN/SSC, Primate Specialist Group (não publicado). 40p.
Ayres, J. M. \& Ayres, C.

1979 - Aspectos da caça no alto rio Aripuanà Acta Amazonica, 9 (2): 287-298.

BATES, H. W.

1863 - "The Naturalist on the River Amazonas". John Murray, London. 389p.

BEST, R. C.

s/d a - Foods and feedig Habitats of wild and captive Sirenia. In: Manual Revierv. 78p. (no prelo).

$\mathrm{s} / \mathrm{d} \mathrm{b}$ - Seasonal breeding in the Amazonian manatee Trichechus inunguis (Mammalia: Sire nia). Biotropica: (no prelo)

Brown, K, S.

1977 - Centros de evolução refúgios quaternários e conservação de patrimônio genéticos na região neotropical: padrões de diferenciação. Ithoniinae (Lepidoptera: Nymphalidae) Acta Amazonica, 7: 75-137.

BRown, K. S.; SHEPPARD, P. M. \& TURNER, J. R.

1974 - Quaternary refugia in tropical America : evidence from race formation in Heliconius butterflies. Proc. Royal Society, (B), 187: 369-378.

Cabrera, A.

1957 - Catalogo de los Mamiferos de America del Sur. Rev. Mus. Argent. Cienc. Natur. "Bernardino Rivadavia", 1 - 2: 1-732.

Cardoso, F. H. \& Müller, G.

1978 -- Amazônia : - Expansão do Capitalismo. CEBRAP, ed. Brasiliense. 208p.

Carvalho, A. I.

1951 - Os jacarés do Brasil. Arq. Mus. Nac. (Rio de Janeiro), 42 (1): 125-139.

Carvalho, J. C.

1967 - A conservação da natureza e recursos na turais na Amazônia Brasileira. Atas Simp. Biota Amazônica, 7: 1-47.

CoImbra- Filho, A. F.

1972 - Mamíferos ameaçados de extinção no Brasil. In: Espécies da Fauna Brasileira Amea çadas de extinção. Academia Brasileira de Ciências editora, Rio de Janeiro, GB. p. 13-92.

DEKRER, D-

1978 - Die Sirene von Amsterdan. Der Zoofreund, 27: 6-7.

DOUGHTY, R- W. \& MYERs, N.

1971 - Notes on the Amazon Wildlife trade. Biol. Cons., 3 (4): 293-297.

Fearnside, P. M-

1979 - Cattle yield predicticn for the transamazon highway of Brazil. Interciencia, 4 (4): 220 226. 
FitTKaU, E- J.

1969 - The Fauna of South America. In: Biogeography and Ecology of South America. Edited by E. J. Fittkau, J. Illies, H. Klinge G. H. Schwabe, H. Sioli, 2. p. 624-657.

Fearnside, P. M- \& Rankin, J. M.

- Avaliação da Jari Florestal e Agropecuária, Ltda. como modelo para o desenvolvimento da Amazònia. Acta Amazonica : (no prelo).

FittKau, E- J. \& Kllskge, H.

1973 - On biomass and trophic structure of the Central Amazonian rain forest ecosystem. Biotropica, 5 (1): 2-14.

FOODEN, J.

1965 - A revision of the woolly monkeys (Genus Lagothrix). J. Mammal, 44: 213-247.

ForshaW, J. M- \& COOPER, W. T.

1973 - Parrots of the World. Lansdowne Press, Australia. 584p.

FOWLER, J. M- \& COPE, J. B.

1964 - Notes on the Harpy Eagle in British Guiana. The Auk, 81: 257-273.

GIL.ES, R. H.

1969 - Wildlife Management Techniques. 3 rd. edition, The Wildlife Society, Washington, D C.

Gonzalez, E. \& Parra, R.

1975 - The capybara, a meat producing animal for the flooded areas of the tropics. Proc. Third World Conf. on Animal Production, T. L. Reid, editor, Sydney, Australia. p. 81-86.

Goodland, R. \& IRwiN, H.

1975 - A Selva Amazônica : Do Inferno Verde ao Deserto Vermelho. EDUSP, Livraria Itatiaia Editora Ltda. 156p.

Granda, A. M. \& Maxweli, J. M.

1978 - The behavior of turtles in the sea, in froshwater and on land. In: Behavior of Fish and the Aquatic Animals. Editado por D. I. Mostofsky, Academic Press. N. Y. 393p.

GRIMWOOD, I.

1968 - The distribution and status of some Peruvian mammals. New York Zoological Society, Special publication, 21: 1-89.

Gross, D.

1975 - Protein Capture and Cultural Development in the Amazon Basin. Am. Anthrop, 77: 527-549.

HAFFER, J.

1969 - Speciation in Amazonian forest birds. Science, 165: 131-137.

1974 - Avian speciaton in tropical South America, with a systematic survey of the toucans (Ramphastidae) and Jacamars (Galbulidae). Públ. Nuttall Orn. Clube, 14: 1-390.
HaGManN, G.

1909 - Die Reptilien der Insel Mexiana, Amazo. nerstrom. Zool. Jahrd., (syst), 28: 473-504.

HART'MAN, D. S.

1968 - The Status of the Florida manatee in captivity. Dep. of Nat. Res. Talahassee Fla., Manuscript.. 22p.

Hernandez-Camacho, J. \& CoOper, R.

1976 - The nonhuman primates of Colombia. In: "Neotropical Primates: Field Studies and Conservation". R. W. Thorington \& P. C. Heltne, eds National Academy of Sciences, Washington, D. C. p. 35-69.

Hershkovitz, $P$.

1961 - On the South American Small-eared Zorro: Atelocynus microtis Scatler (Canidae). Fieldiana (Zool.), 39 (44): 503-523.

1963 - A systematic and Zoogeographic account of the monkeys of the genus Callicebus (CEBIDAE) of the Amazonia and Orinoco basins. Mammalia, 27 (1): $1-79$.

1978 - Living New World Monkeys (Platyrrhini) with introduction to Primates. The University of Chicago Press. p. 1-1117.

HICK, U.

1968 -Erstmalig gelungene zucht eines bartsakis im Kölner Zoo. Kölner Zoo, 11 (2): 35-41.

HIDROSERVICE

1973 - Engenharia de projetos. Plano de Desenvolvimento Integrado da Area da bacia do rio Tocantins, HE 156-RIO-0873. São Paulo, 1: $202 p$.

Hill, W. C. O.

1960 - Primates. Comparative Anatomy and Taxonomy. Vol. IV, Cebidae, Part A, Univ. Press, Edinburgh. 523p.

IANNI, $O$.

1979 - A luta pela terra. Ed. Voves, Petrópolis, $2 a$. ed. 235p

IBDF

1979 - Plano do Sistema de Unidades de Conservação do Brasil. Ministério da Agricultura, Instituto Brasileiro de Desenvolvimento Florestal (IBDF) e Fundação Brasileira para Conservação da Natureza (FBCN), Brasília. $107 p$.

INCRA

1974 - Estatísticas Cadastrais 1 / Recadastramento de 1972. Sistema Nacional de Cadast:o Rural de Imóveis. Brasília D.F., Ministério da Agricultura.

IUCN

1974 - Red Data Book. Mammalia, 1.

1977 - Bulletin. 4 (8): 1-16. 
JUNK, W. J.

1975 - Aquatic Wildlife and Fisheries. The use of Ecological guidelines for Development in the American Humid Tropics. IUCN Procee. dings. p. 109-126.

Kalter, S. S. JR,; Heberling, \& Malherbe, H

1976 - Use and problems in with nohuman primates in biomedical research. In the laboratory Animal. In: The Study of Reproduction. 6 th. ICLA Symposiuns Thessdoniki 1975. Edited by The Antikatzides, S. Erichgen, A. Spiegel, Gustav Fischer Verlag, Stuttgart, New York.

KLEIN, L. L. \& KI.EIN, D. J

1973 - Observations on two types of neotropical primate intertaxa associations. Amer. J. Phys. Anthropol., 38 (2): 649-653.

LOVEJOY, $\mathrm{T}$.

1979 - Designing Refugia for tomorrow. Proceedings Fifth Symposium of the Association for Tropical Biology: (no prelo).

Medem, F.

1963 - Osteologia craneal, distribuition geográfica y ecologia de Melanosuchus niger (Spix) (Crocodylia, Alligatoridae). Rev. Acad. Colomb. C., 12 (45): 5-19.

1971a- Situation report on crocodilians from three South American countries. In: Crocodilos. International Union for conservation of Nature and Natural Resources Publ. (N.S ) Suppl. Pap. 32 (1): 54-71.

1971 - Biological isolation of sympatric species in South American Crocodilia. In: Crocodiles. International Union for Conservation of $\mathrm{Na}$ ture and Natural Resources Publ. (N.S.), Suppl. Pap., 32 (1): 152-158.

Mendes, A.

1938 - As pescarias amazônicas e a piscicultura no Brasil (Notas e Sugestões). Livraria Editora Record, São Paulo. 181p.

Meyer de Schauensee, R.

1966 - Species of birds of South America and their distribution. Publ. Acad. Nat. Science, 18: $1-578$.

MITTERMEIER, R. A.

1978 - South America's river turtles: Saving them by use. Oryx, 14 (3): 222-230

MitTermeier, R. A. \& COIMBra-Filho, A. F.

1977 - Primate Conservation in Brazilian Amazônia. In: Primate Conservation. Ed. by Prince Rai nier and Bourne, 5: 117-166.

MON'gomery, G. G. \& LUBIN, Y. D.

1977 - Prey influences on movements of neotropical anteaters. In: Proceedings of the 1975 predator Symposium. Edited by $\mathrm{R}$ L. Phillips and C. Jonkel, Univ. Montana. p. 103. 132 .
MYERS, N.

1976 - An Expanded Approach to the Problem of Disappearing Species. Science, 193: 198-202.

NAPIER, P. H.

1976 - Cataloque of Primates of the British Museum (Natural History), Part I. Families Cebidae and Callithrichidae. British Mus. Nat. Hist., London. 121p.

NAPIER, J. R. \& NAPIER, P $H$.

1967 - A handbook of Living Primates. Academic Press, New York. 456p.

NICÉFORO, M.

1955 - El caimãn yacaré negro (Melanosuchus niger Spix) en Colombia. Caldasia (Bogotá), 7 (32): 167-171.

Novats, F. C.

1978 - Sobre algumas aves pouco conhecidas da Amazônia Brasileira II. Boletím do Mus. Paraense Emílio Goeldi, Nova Série. Zoologia, 90: $15 p$

OJASTI, J.

1973 - Estudio biologico del Cheguire o capybara. Caracas, Fonde National de Investigaciones Agropecuárias. 273p.

OJasti, J. \& Padilha, G. M.

1972 - The management of capybara in Venezuela Reprinted from Transactions of the thirtySeventh North American Wildlife and Natural Resources Conference March 12-15, 1972. Published by the Wildlife Management Institute, Wire Building, Washington, D. C. 20005. p. 268-277.

PANDOLFO, C.

1978 - A floresta Amazônica Brasileira Enfoque Econômico - Ecológico. Departamento de Recursos Naturais - SUDAM - Ministério do Interior, Belém. 118p.

Pereira, N.

1944 - O peixe-boi da Amazônia. Bol. Minist. Agricultura, Rio de Janeiro, 33: 21-95.

Pinto, L. F.

1977 - Amazônia : O Anteato da destruição. Graịisa, Belém, Pará. 372p.

PierReT, P. V.

1967 -- Inportancia de la caza para alimentaçion humana en el curso inferior del $\mathbf{R}$. Ucayali. Rev. Forest Peru, 1 (2): 10-21.

Polamazonia

1977 - Programa de Polos Agropecuários e Agrominerais da Amazônia. Ministério do Interior, Polo Carajás (SUDAM). 168p

Pook, A. G. \& Pook, G.

1979 - A field study on the Status and Socio-ecology of the Goeldi's Monkey (Callimico Goeldi) and other Primates in Nothern Bolivia. Umpublished manuscript. 37p. 
Prance, G. T.

1973 - Phytogeographic support for the theory of Pleistocene forest refuges in the Amazon basin, based on evidence from distribution patterns in Caryocaraceae, Crysobalanaceae, Dichapetalaceae and Lecythidaceae. Acta Amazônica, 3: 5-28.

Rego, A. R. DE M.

1944 - O peixe-boi. Rev. Mus. Nat., 2: 10-12.

ROBERTS, T. R.

1972 -- Ecology of fishes in the Amazon and Congo basins. Bull. Mus. Comp. Zool, 143 (2): 117-147.

Ross, E. B.

1978 - Food Taboos, diet and Runting Strategy : the Adaptation to Animals in Amazon Cultural Ecology Curr. Anthrop. 19 (1): 1-36.

SANTOS, $R$.

1977 - Sistema de propriedades e relações de Trabalho no meio rural paraense. Núcleo de Altos Estudos Amazônicos (NAEA), UFPa, Belém-Pará. 37p

SCHMITHÜSEN, F.

1978 - Contratos de Utilização Florestal com Referência Especial a Amazônia Brasileira. Projeto de Desenvolvimento e Pesquisa Florestal, PNUD / FAO / IBDF, Brasília, DF. 35p.

SCHUBART, H. $O$.

1977 - Critério ecológico para o desenvolvimento agrícola das terras firmes da Amazônia. Acta Amazonica, 7 (4): 559-567.

S.E.M.A.

1977 - Programa de estações ecológicas. Secretaria Especial de Meio Ambiente (SEMA), Brasília. 41p.

SHRIMPTON, R.

1977 - Perspectivas das anemias na Amazônia. Trabalho apresentado no Seminário sobre as anemias nutricionais do Brasil no INAM, MS., Brasília.

Shrimpton, R.; Giugliano, R. \& Giugliano, !.. G.

1978 - Preliminary Observations on chronic human Zinc deficiency, in Amazonas - Brazil. Trabalho apresentado no XI Congresso Internacional de Nutrição. Rio de Janeiro, Setembro.

Sick, $\mathbf{H}$,

1967 - Rios e enchentes na Amazônia como obstáculos para a avifauna. At. Simpos. Biota Amazônica, 5 (Zool): 495-520.

1972 - A Ameaça da Avî́rauna Brasileira. In: Espé. cies da Fauna Brasileira Ameaçadas de Extinção. Ed. pela Academia Brasileìra de Ciên. cias / CNPq / FNDCT. p. 99-153.
SMITH, N. J. H.

1974 - Destructive Explortation of the South American River Turtle. Yearbook Assoc. Pacific Coast Geog., 36 (1): 85-101.

1976 - Utilization of game along Brazil's Transa. mazon highway. Acta Amazonica, 6 (4): 455-466.

1977 - Influências culturais e ecológicas na produtividade agrícola ao longo da Transamazônica. Acta Amazonica, 7 (1): 23-38.

1978 - Human Explortation of Terra Firme Fauna in Amazonia. Ciência e Cultura, 30 (1): 17-23.

1979 -- Quelônios aquáticos da Amazônia : um recurso ameaçado. Acta Amazonica, 9 (1): 87-97.

SoINI, P.

1972 - The capture and commerce of live monkeys in the Amazonian region of Peru. International Zoo Yearbook, 12: 26-36.

STATon, M. \& Dixon, J.

1975 - Studies on the dry Season biology of Caiman crocodilus from the Venezuelan Llanos. Memoria de la Sociedad de Ciências Natureles Salle, 101 (35): 237-265.

1977 - Breeding Biology of the Spectacled Caiman, Caiman crocodilus crocodilus, in the Venezuelan Llanos. United States Department of the Interior Fish and Wildlife Service, Wildlife Research Report, 5. 21p.

Tardin, A. T.; Santos, A. P. dos; Lee, D. C. L.;

Maia, F. C. S.; MEndonçA, F. J.; AsSunção, C. V.;

Rodrigues, J. E.; Moura ABdon, M. DE; Novaes, R. A.; Chen, S. C.; Duarte, V. \& Shimabukuro, Y. E.

1979 - Levantamento de área de desmatamento na Amazônia Legal através de imagens de satélite LANDSAT. (INPE - COM. 3/NTE, C.D.U. 621.38SR). Instituto Nacional de Pesquisas Especiais, São José dos Campos, SP. 9p.

Vanzolini, P. E.

1972 - Répteis e anfíbios ameaçados de extinção no Brasil. In: Espécies da fauna brasileira ameaçadas de extìnção. Rio de Janeiro, Academia Brasileira de Ciências. p. 155-157.

1973 -- Paleoclimates, relief and species multiplication in equatorial forest. In: Tropical Forest Ecosystems in Africa and South America: A Comparative Review. B. J. Meggers, E. S. Ayensu and W. D. Duckworth, eds, Smithsonian Institution Press. p. 255-258.

Vanzolini, P. E.; \& Gomes, N.

1979 - Notes on the ecology and growth of Amazonian Caimans (crocodylia, Alligatoridae). Papéis Avulsos de Zoologia, 32 (17): 205-216. 
VAURIE, $C$.

1968 - Taxonomy of the Cracidae (Aves). Bull. Am. Mus. Nat. Hist., 138 (4): 131-260.

VERÍsSIMo, J.

1970 - A pesca na Amazônia. Livraria Clássica da Alves \& C.: $130 p$.

VIEIRA, C. C.

1955 - Lista remissiva dos mamíferos do Brasi'. Arq. Zool., São Paulo, 8: 341-474.

THORINGTON, R. W.

1969 - The study and Conservation of New World Monkeys. In: Simpósio sobre a Conservação da Natureza e Restauração do Ambiente Natural do Homem. p. 253-310.

WALKer, E. P. et al.

1968 - Mammals of the world. The Johns Hopkins Press, Baltimore, 1-2. 1500p.
Wetterberg, G. B.; Ferreira, M.; Brito, W. L. S. \& Araújo, V. C.

1976 - Espécies da fauna amazônica potencialmente preferidas para consumo nos restauran tes de Manaus. Brasif Florestal, 7 (25): 5859 .

Wetterberg, G. B.; PÁdua, M. T. J.; Castro, C. S.

\& Vasconcelos, J. M. C.

1977 - Uma análise de prioridades em conservação da Natureza na Amazônia. Ministério da Agricultura, Brasília, Série Técnica, 8 (114): $1-6$.

Wetterberg, G. B. \& Pádua, M. T. J.

1978 -. Preservação da natureza na Amazônia Brasileira, situação em 1978. FAO / PNUD i IBDF. Brasília, Série Técnica, 13: 1-44. 